\title{
Pengembangan Modul Sistem Peredaran Darah Berbasis Inkuiri berdasarkan Hasil Penelitian Diabetes Mellitus Tipe 2
}

\author{
Dita Purwinda Anggrella $^{1]}$, Sri Endah Indriwati ${ }^{2]}$, Sri Rahayu Lestari ${ }^{3]}$ \\ ${ }^{1}$ IAIN Surakarta, \\ ${ }^{2,3}$ Universitas Negeri Malang \\ E-mail: ${ }^{1]}$ dita.anggrella@iain-surakarta.ac.id \\ ${ }^{2]}$ sri.endah.fmipa@um.ac.id \\ ${ }^{3]}$ srirahayulestari@um.ac.id
}

\begin{abstract}
Abstrak
Upaya dalam perkembangan IPTEK dalam pendidikan dapat dilakukan salah satunya dengan memfasilitasi mahasiswa dengan bahan ajar berbasis penelitian. Berdasarkan analisis kebutuhan mahasiswa akan bahan ajar pada materi sistem peredaran darah, dibutuhkan bahan ajar berupa modul. Pengembangan modul dalam penelitian ini bertujuan untuk menghasilkan modul sistem peredaran darah berbasis inkuiri berdasarkan hasil penelitian diabetes mellitus tipe 2 yang telah teruji kelayakan, kepraktisan, dan keefektifannya. Metode dalam pengembangan modul ini menggunakan Research and Development $(R \& D)$ yaitu model pengembangan Branch yang terdiri dari Analyze, Design, Development, Ilmplementation and Evaluation. Pengumpulan data penelitian berdasarkan penilaian dari valiadator ahli melalui instrumen validasi, dan subjek uji coba penelitian yaitu mahasiswa IKIP Budi Utomo Malang yang terdiri dari 9 mahasiswa dalam uji coba kelompok kecil dan 23 mahasiswa dalam uji coba kelompok besar melalui instrumen angket. Instrument hasil dari penelitian kemudian di analisis secara deskriptif. Hasil penelitian menunjukkan bahwa uji validitas materi diperoleh persentase sebesar 90,2\%, hasil validasi pengembangan bahan ajar untuk mahasiswa diperoleh persentase $94,75 \%$, dan $94 \%$ untuk modul pegangan dosen, persentase untuk praktisi pembelajaran sebesar 96,6\%. Persentase uji coba kelompok kecil yang digunakan di lapangan sebesar 87,04\% dan 98,67\% untuk uji coba kelompok besar. Berdasarkan hasil validasi oleh ahli materi, pengembangan bahan ajar, dan praktisi lapangan maka dapat disimpulkan modul yang dikembangkan sebagai sumber belajar mahasiswa sangat valid dan sangat layak digunakan.
\end{abstract}

Kata Kunci: Modul berbasis inkuiri, Sistem peredaran darah, Diabetes mellitus tipe 2

\section{Development of Inquiry Based Circulation System Module Based on Result of Diabetes Mellitus Type 2}

\begin{abstract}
The development of science and technology in education can be carried out one of them by facilitating students with research-based teaching materials. Based on the analysis of student needs for teaching materials in the circulation system, required teaching materials in the form of modules. The development of modules in this study aims to produce inquiry-based circulatory system modules based on the results of type 2 diabetes mellitus research that have been tested for their suitability, practicality, and effectiveness. The method in developing this
\end{abstract}


module uses Research and Development $(R \& D)$, which is a Branch development model consisting of Analyze, Design, Development, Implementation and Evaluation. Research data collection was based on the assessment of expert valiadators through validation instruments, and the subjects of the research trials were IKIP Budi Utomo Malang students consisting of 9 students in small group trials and 23 students in large group trials through questionnaire instruments. Instrument results from the study were then analyzed descriptively. The results showed that the validity test of the material obtained a percentage of $90.2 \%$, the results of the validation of the development of teaching materials for students obtained a percentage of $94.75 \%$, and $94 \%$ for the lecturer grip module, the percentage for learning practitioners was 96.6\%. The percentage of small group trials used in the field is $87.04 \%$ and $98.67 \%$ for large group trials. Based on the results of the validation by the material experts, the development of teaching materials, and field practitioners, it can be concluded that the module developed as a source of student learning is very valid and very feasible to use.

Keywords: Inquiry-based modules, Circulatory system, Type 2 diabetes mellitus

\section{PENDAHULUAN}

Kurikulum di Indonesia merupakan acuan dasar pendidikan yang berisikan capaian pembelajaran lulusan, bahan kajian, proses, dan penilaian yang digunakan sebagai pedoman penyelenggaraan program studi pada Perguruan Tinggi (Kemenristedikti, 2016). Pembaharuan kurikulum di perguruan tinggi menuntut agar capaian lulusan tidak hanya membentuk pengetahuan mahasiswa, namun juga karakter dan keterampilan mahasiswa yang diiringi dengan perkembangn ilmu pengetahuan dan teknologi (IPTEK) (Jamun, 2018).

Upaya perkembangan IPTEK dalam pendidikan dapat diterapkan dalam pelaksanaan pembelajaran, seperti memanfaatkan IPTEK dalam pengimplementasian hasil penelitian melalui pembelajaran berbasis riset atau penelitian (Slameto 2015). Pembelajaran berbasis riset merupakan pendekatan berbasis student center learning dengan mengintegrasikan riset dalam proses pembelajaran. Strategi dalam mendukung pembelajaran berbasis riset salah satunya adalah dengan memperkaya bahan ajar dengan hasil penelitian (Umar et al. 2011).
Pembelajaran berbasis riset terdiri dari tiga tahapan, yaitu (1) eksposure stage, untuk mengetahui kemampuan dari mahasiswa, (2) experience stage, memberikan pengalaman melalui penelitian, dan (3) capstone stage, menampilkan hasil riset bak secara lisan maupun tulisan (Tangi, 2016).

Institut Keguruan dan Ilmu Pendidikan (IKIP) Budi Utomo Malang merupakan salah satu Perguruan Tinggi swasta yang berbasis kependidikan dan keguruan di Kota Malang yang menaungi program studi pendidikan biologi dengan memiliki rancangan kurikulum yang belum secara menyeluruh memafaatkan IPTEK dalam pembelajarannya. Hal ini dapat dilihat berdasarkan hasil analisis kebutuhan di IKIP Budi Utomo malang pada matakuliah anatomi fisiologi manusia

Hasil observasi yang ditemukan di lapangan, menunjukkan adanya kesenjangan antara capaian pembelajaran dengan kondisi yang sebenarnya, bahwa capaian pembelajaran dalam mengembangkan keterampilan di laboratorium pada matakuliah Anatomi Fisiologi Manusia masih belum dilakukan secara maksimal. Kesenjangan tersebut 
disebabkan oleh jam perkuliahan yang tidak mengakomodasi seluruh kegiatan teori dan praktikum yang diperlukan dalam matakuliah Anatomi Fisiologi Manusia karena kurangnya sarana dan prasarana, sehingga capaian pembelajaran yang dirumuskan dalam tujuan pembelajaran juga belum tercapai secara maksimal.

Tidak tercapainya capaian pembelajaran pada matakuliah Anatomi Fisiologi Manusia didukung berdasarkan hasil angket analisis kebutuhan mengenai permasalahan pada matakuliah Anatomi Fisiologi Manusia. $62,5 \%$ mahasiswa mengungkapkan bahwa materi sistem peredaran darah pada matakuliah Anatomi Fisiologi Manusia merupakan salah satu materi yang dianggap sulit dipahami oleh mahasiswa karena materinya yang abstrak, bersifat teoritis, kurangnya sumber belajar dan tidak adanya kegiatan praktikum yang menunjang mahasiswa dalam memperoleh konsep.

Berdasarkan analisis kebutuhan tersebut, maka diperlukannya adanya inovasi berupa bahan ajar untuk mendukung proses pembelajaran khususnya pada materi sistem peredaran darah matakuliah anatomi fisiologi manusia. Bahan ajar yang cocok digunakan untuk mendukung perkuliahan matakuliah anatomi fisiologi manusia ini adalah modul. Anwar (2010) mengungkapkan modul pembelajaran merupakan bahan ajar yang dapat digunakan secara mandiri dan disusun secara sistematis serta menarik yang mencakup isi materi, metode dan evaluasi untuk mencapai kompetensi yang diharapkan. Pemilihan modul sebagai sumber belajar juga memperhatikan dari kondisi sarana dan prasarana yang ada di IKIP Budi Utomo Malang yang kurang menunjang apabila menggunakan media elektronik. Kelebihan modul dalam pembelajaran adalah fokus dalam kemampuan individual mahasiswa (Utami, 2018; Diana dkk, 2018; Puspitasari, 2019), serta adanya control terhadap hasil belajar karena didalamnya sudah terintegrasi dengan pengalaman belajar terencana melalui penggunaan standart kompetensi yang akan dicapai oleh mahasiswa (Pratiwi dkk, 2017).

Solusi perbaikan yang diharapkan adalah tersedianya bahan ajar berupa modul yang dapat mendukung kegiatan ilmiah mahasiswa, karena untuk memahami suatu konsep, mahasisiwa tidak hanya dengan menghafalkan teori yang diperolehnya, namun dapat mempraktekkannya melalui kegiatan ilmiah. Kegiatan ilmiah dapat didukung dengan model pembelajaran inkuiri. Model pembelajaran inkuiri memberikan kesempatan mahasiswa melakukan penyelidikan dan mendapatkan konsep yang lebih dalam dan luas karena dapat mengkonstruk pengetahuan yang baru (Ergul et al, 2017; Ozgur and Yilmaz, 2017), sehingga menjadi pemikir yang kritis (Vlassi and Karaliota 2013). Hasil penelitian Nurochma (2012) membuktikan bahwa model guided inquiry berhasil dalam meningkatkan hasil belajar ranah kognitif. Penerapan pembelajaran berbasis inkuiri secara signifikan juga dapat meningkatkan keterampilan proses sains (Muzaffar et al, 2011; Dewi et al, 2017) dan hasil belajar (Abdi, 2014; Furqan dkk, 2016; Yulita, 2018), serta kemampuan menganalisis (Karlina et al, 2018) dalam pemecahan masalah (Betty et al, 2016). Model pembelajaran inquiry juga dapat meningkatkan motivasi belajar (Ozgur and Yilmaz, 2017) karena memberikan kebebasan siswa dalam membuat pilihan mereka sendiri dalam mengambil proyek yang mereka minati (Bayram et al, 2013), mengeksplorasi, dan menguraikan sains (Chung and 
Behan, 2010).

Kegiatan Inkuiri selalu berkaitan dengan kegiatan ilmiah (Lliwellyn, 2013). Kegiatan ilmiah akan lebih mudah penerapannya apabila didukung dengan pembelajaran yang kontekstual. Artinya kegiatan ilmiah melibatkan kehidupan sehari-hari yang ada di lingkungan sekitar akan memudahkan mahasiswa dalam menemukan suatu konsep. Hal ini didukung oleh pernyataan Espinoza and Quarless (2010) bahwa pembelajaran kontekstual dapat mengembangkan keterampilan berpikir kritis dan keterampilan berpikir ilmiah (Suryawati and Osman, 2017) karena mampu menghubungkan teori dengan kehidupan sehari-hari. Alternatif pembelajaran yang didukung dengan hasil penelitian diharapkan dapat menjadikan pembelajaran lebih kontekstual. Proses Pembelajaran kontekstual menekankan pada tiga hal yaitu, pertama pembelajaran kontekstual yang diorientasikan pada proses pengalaman secara langsung. Kedua, pembelajaran kontekstual mendorong agar mahasiswa dapat menemukan hubungan antara materi yang dipelajari dengan realitas kehidupan nyata. Ketiga, pembelajaran kontekstual mendorong mahasiswa untuk dapat menerapkannya dalam kehidupan sehari-hari berdasarkan konsep yang telah didapat. Penelitian (Fatmala and Sujana, 2017; Choerunnisa and Wardani, 2017) membuktikan pembelajaran kontekstual berpengaruh terhadap literasi sains dari segi konten, konteks, dan sikap sains siswa secara signifikan meningkat. Supriyadi and Waremra (2019) dalam penelitiannya mengintegrasikan pendekatan kontekstual dengan kearifan lokal membuktikan pembelajaran menjadi lebih bermakna.

Salah satu kelainan penyakit yang dapat dikontekstualkan dalam pembelajaran berkaitan dengan materi sistem peredaran darah adalah diabetes mellitus (DM), pemilihan penyakit diabetes sebagai contoh pembelajaran yang kontekstual karena penyakit ini merupakan salah satu penyakit kronik yang banyak di derita oleh masyarakat dunia. International Diabetes Federation (IDF) pada tahun 2017 memperkirakan sekitar $87-91 \%$ orang di dunia menderita Diabetes Mellitus Tipe 2 (DMT2), 2,7-12\% menderita Diabetes Mellitus Tipe 1 (DMT1), dan 1-3\% menderita DM tipe lain. Jumlah penderita DMT2 di Indonesia sendiri akan terjadi peningkatan dari 7 juta menjadi 12 juta pada tahun 2030 .

Pembelajaran kontekstual dapat ditampilkan melalui pembelajaran berbasis riset. Pembelajaran berbasis riset yaitu metode pembelajaran kooperatif mencakup authentic learning, problem-solving, contextual and inquiry discovery approach secara kontruktivisme (Widayati, 2010). Temuan (Slameto 2015) secara signifikan menunjukkan pembelajaran berbasis riset melalui inquiry based learning mampu meningkatkan 21,5\% hasil belajar. Hasil riset DMT2 diharapkan dapat memberikan wawasan yang lebih kepada mahasiswa tentang perkembangan IPTEK dan dapat membantu mahasiswa dalam mengaitkan hasil penelitian DM dengan materi sistem peredaran darah pada matakuliah anatomi fisioologi manusia. Berdasarkan uraian diatas, maka solusi yang dapat ditawarkan dalam mengatasi permasalahan yang ada di IKIP Budi Utomo Malang adalah dengan dilakukannya pengembangan modul berbasis inkuiri dengan pendekatan kontekstual yaitu berdasarkan penelitian laboratorium DMT2. 


\section{METODE}

Penelitian dalam pengembangan modul ini menggunakan model Research dan Development ( $\&$ \&) yang dikembangkan oleh Branch (2009) meliputi tahapan Analyse, Design, Development, Implementation, dan Evaluasion (ADDIE). Setiap tahapan dari model ini memiliki keterkaitan dan terdapat evaluasi dalam setiap tahapan, sehingga dapat diketahui kekurangan tiap tahapannya. Prosedur tiap tahapan ADDIE sebagai berikut:

\section{a. Analyze (Analisis)}

Tahapan pada analyze: a) peneliti melakukan analisis yaitu mengidentifikasi masalah yang ada di IKIP Budi Utomo Malang melalui wawancara terhadap dosen pengampu matakuliah, penyebaran angket pada mahasiswa serta observasi lapangan. Identifikasi malasah meliputi kendala media belajar, bahan ajar, metode dan model pembelajaran; b) peneliti menentukan tujuan dari pengembangan, dengan memilih beberapa produk yang akan dikembangkan sesuai dengan kondisi dan kebutuhan yang ada di IKIP Budi Utomo pada materi sistem peredaran darah; c) peneliti menentukan sasaran dari pengembangan produk, dengan memilih produk yang dapat mendukung kegiatan praktikum atau kegiatan ilmiah dalam pemahaman konsep mahasiswa; d) peneliti mengidentifikasi hal yang dibutuhkan dalam mendukung produk yang akan dikembangkan; e) peneliti mengevaluasi beberapa bentuk produk, dan dipilih produk terbaik yang memiliki potensi besar dalam mengatasi permasalahan yang ditemukan pada saat analisis kebutuhan; f) peneliti menyusun rencana dalam merancang produk yang akan dikembangkan.

\section{b. Design (perancangan)}

Tahap design, peneliti merancang isi dari pengembangan produk dengan: a) mendadaftar seluruh komponen dalam produk mulai dari materi pembelajaran berdasarkan capaian matakuliah, kegiatan berdasarkan model pembelajaran, dan persiapan penelitian laboratorium yaitu Diabetes mellitus tipe 2 pada hewan uji coba; b) peneliti menyusun tujuan dalam pengembangan modul, sehingga dihasilkan modul yang dapat mengatasi permasalahan di IKIP Budi Utomo yaitu modul yang mendukung kegiatan praktikum atau kegiatan ilmiah mahasiswa; c) peneliti menyusun strategi penilaian, berdasarkan hasil dari perancangan dievaluasi untuk dijadikan pedoman dalam membuat lembar validasi untuk dinilai oleh validator ahli.

\section{c. Development (pengembangan)}

Kegiatan pada tahap development yaitu: a) mengembangkan produk mulai dari menyusun isi/materi dan kegiatan yang telah dirancang pada tahap design, kemudian divalidasi oleh ahli materi, ahli bahan ajar serta praktisis lapangan untuk menilai kelayakan produk; b) hasil penilaian dari validator ahli kemudian dievaluasi dan dilakukan revisi perbaikan sehingga dihasilkan modul yang siap untuk diimplementasikan.

\section{d. Implementasi (penggunaan)}

Kegiatan implementasi

dilakukan untuk menguji keefektifan modul yang dikembangkan pada kondisi pembelajaran yang sebenarnya. Uji coba produk di lapangan skala kecil dilakukan dengan tujuan untuk mengetahui efektifitas dari modul yang telah direvisi sebelumnya dan untuk memperoleh masukan untuk produk modul. Efektivitas dari modul dilakukan 
pengisian angket validasi oleh mahasiswa yang telah menempuh matakuliah Anatomi Fisiologi Manusia. Pemilihan sampel dilakukan secara purposive sampling yaitu mahasiswa yang telah menempuh matakuliah Anatomi Fisiologi Manusia.

\section{e. Evaluation (penilaian)}

Tahap ini dilaksanakan dalam bentuk evaluasi formatif dan sumatif. Evaluasi formatif dilakukan untuk menjamin kualitas produk modul yang dikembangkan dan dilakukan tiap akhir tahap pengembangan. Evaluasi sumatif untuk mencapai tujuan dari pengembangan yaitu menghasilkan produk yang layak, praktis, dan efektif digunakan oleh mahasiswa.

Teknik analisa data digunakan untuk mengubah data kuantitatif menjadi bentuk persentase sehingga kevalidannya dapat diinterpretasikan:

Keterangan:

$$
V=\frac{T s e}{T s h} X 100 \%
$$

$\mathrm{V}=$ validasi ahli

Tse $=$ pencapaian total skor empiric validator

Tsh $=$ skor maksimal yang diharapkan $100 \%=$ konstanta

Modul dapat dikatakan valid dan praktis apabila tingkat kevalidan minimum level $60 \%$. Kriteria kevalidan dan kepraktisan data angket penilaian dari validator dapat dilihat pada Tabel 1.

\section{Tabel 1. Kriteria Kevalidan Data}

\begin{tabular}{|c|c|}
\hline \multicolumn{2}{|c|}{ Angket Penilaian Validator } \\
\hline $\begin{array}{c}\text { Skor } \\
\text { nilai }(\%)\end{array}$ & Keterangan \\
\hline $81-100$ & $\begin{array}{l}\text { Sangat valid; sangat praktis; } \\
\text { dapat digunkan tapa } \\
\text { perbaikan }\end{array}$ \\
\hline $61-80$ & $\begin{array}{ll}\text { Valid; praktis; } & \text { dapat } \\
\text { digunakan namun } & \text { perlu } \\
\text { perbaikan kecil } & \end{array}$ \\
\hline $1-60$ & Cukup valid; cukup praktis; \\
\hline
\end{tabular}

\begin{tabular}{lll} 
21-40 & \multicolumn{3}{l}{ disarankan tidak digunakan } \\
& $\begin{array}{l}\text { Kurang valid; } \\
\text { praktis; tidak }\end{array}$ & dapang \\
digunakan & dapat \\
$0-20$ & $\begin{array}{l}\text { Tidak valid; tidak praktis; } \\
\text { tidak dapat digunakan }\end{array}$ \\
\hline
\end{tabular}

(Sumber: Akbar, 2013)

\section{HASIL DAN PEMBAHASAN}

Hasil dari pengembagan produk modul terdiri dari data kuantitatif dan kualitatif yang dijabarkan berdasarkan tahapan ADDIE sebagai berikut:

\section{a. Analyze}

Hal pertama yang dilakukan pada tahap analyze adalah memvalidasi kesenjangan antara harapan dan fakta yang dilakukan melalui analisis kebutuhan. Hasil analisis kebutuhan terhadap kondisi awal di lapangan melalui observasi, wawancara, dan pembagian angket terhadap mahasiswa IKIP Budi Utomo Malang menunjukkan kegiatan belajar mahasiswa masih terkendala terkait bahan ajar yang kurang menarik, karena materi sistem peredaran darah (kardiovaskular) pada matakuliah anatomi fisologi manusia tergolong materi yang abstrak apabila tidak didukung dengan adanya gambar, maka akan mempengaruhi terhadap pemahaman mahasiswa. Selain itu, berdasarkan observasi, terbatasnya sarana dan prasarana menyebabkan mahasiswa belajar menggunakan papan tulis, sehingga pembelajaran menjadi kurang interaktif. Metode pembelajaran yang digunakan yaitu berupa ceramah, penugasan dan diskusi presentasi, hal ini dikarenakan fasilitas laboratorium yang terbatas, sehingga tidak mengakomodasi semua kegiatan praktikum mahasiswa.

Setelah menganalisis kondisi awal, selanjutnya adalah menentukan tujuan dari pengembangan dengan menawarkan beberapa solusi produk pengembangan yang dapat mendukung 
perkuliahan pada matakuliah anatomi fisiologi manusia. Sasaran dari produk yang akan dikembangkan adalah berupa bahan ajar yang dapat mendukung kegiatan praktikum atau kegiatan ilmiah mahasiswa dengan dapat dipelajari secara mandiri, serta dapat mengaitkannya dengan kehidupan sehari-hari. Sehingga peneliti perlu mengidentifikasi hal yang perlu dibutuhkan untuk mendapatkan produk yang terbaik, yaitu dengan menampilkan model pembelajaran yang berbasis saintifik dengan pendekatan kontekstual pada produk yang akan dikembangkan. Sehingga produk yang paling cocok dari hasil identifikasi adalah bahan ajar berupa modul berbasis inkuiri dengan pendekatan kontekstual berupa hasil penelitian. Setelah ditetapkan produk yang akan dikembangkan, peneliti baru dapat menyusun rencana produk, yaitu meyusun materi sistem peredaran darah yang disusun berdasarkan capaian matakuliah, menetapkan praktikum atau kegiatan ilmiah yang akan dilakukan, dan pendekatan kontekstual yang akan ditampilkan dalam produk yang akan dirancang yaitu penyakit/hasil penelitian dari DMT2.

\section{b. Design}

Kegiatan dari tahap design adalah merancang produk berdasarkan analisis kebutuhan yaitu bahan ajar berupa modul yang dapat mengakomodasi kegiatan praktikum/ kegiatan ilmiah untuk membantu mahasiswa dalam memahami konsep. Hasil dari kegiatan design yaitu: a) merancang isi modul terdiri dari sampul/cover (depan dan belakang), kata pengantar, daftar (isi, tabel, dan gambar), pendahuluan, petunjuk penggunaan modul, capaian dan indikator pembelajaran, peta konsep, BAB I sampai BAB III yang telah dilengkapi dengan latihan soal mandiri beserta self-assessment tiap bab, daftar rujukan, dan glosarium. Materi dalam modul disesuaikan dengan capaian matakuliah sesuai dengan KKNI. Tiap $\mathrm{BAB}$ akan menampilkan kegiatan pembelajaran sesuai dengan model pembelajaran inkuiri dengan pendekatan kontekstual dengan menampilkan fenomena penyakit DM sebagai tahap awal kegiatan inkuiri. Selain itu juga akan dilengkapi dengan hasil penelitian DM tipe 2 sebagai wawasan pengetahuan mahasiswa; b) kegiatan inkuiri dalam modul akan mengakomodasi kegiatan praktikum mahasiswa, dan dengan adanya hasil penelitian DM akan memberikan pembelajaran yang lebih kontekstual dan memberikan mahasiswa wawasan yang lebih luas; c) peneliti merancang instrument valiadasi untuk dinilai oleh validator ahli, sehingga produk yang dirancang valid dan dapat diimplementasikan.

\section{c. Development}

Hasi dari tahap development ini yaitu: Materi yang telah dirancang dalam modul dijabarkan menjadi beberapa indikator pembelajaran, dan dilakukan menjadi 3 kali pertemuan dijabarkan dalam Tabel 2 berikut:

Tabel 2. Indikator Pembelajaran

\begin{tabular}{|c|c|}
\hline BAB & Indikator \\
\hline 1 & Mengidentifikasi komponen darah \\
\hline 2 & $\begin{array}{l}\text { Mengidentifikasi struktur organ } \\
\text { dalam sisitem peredaran darah } \\
\text { Menganalisis keerkaitan antara } \\
\text { struktur organ dan mekanisme } \\
\text { kerja jantung serta perdaran darah }\end{array}$ \\
\hline \multirow[t]{3}{*}{3} & $\begin{array}{l}\text { Menganalisis komponen getah } \\
\text { bening }\end{array}$ \\
\hline & $\begin{array}{l}\text { Menganalisis mekanisme } \\
\text { peredaran getah bening }\end{array}$ \\
\hline & $\begin{array}{l}\text { Menganalisis kelainan sisitem } \\
\text { hemolimfe pada penderita DM }\end{array}$ \\
\hline
\end{tabular}


Modul yang telah dirancang terlebih dahulu divalidasi oleh validator ahli materi, pengembangan bahan ajar, serta praktisi lapangan untuk mengetahui kevalidan dan kelayakan produk. Hasil dari validasi digunakan sebagai dasar untuk perbaikan/revisi sebelum produk diujicobakan kepada mahasiswa.

Validasi materi bertujuan untuk menguji kevalidan isi atau materi dari modul yang dikembangkan. Hasil skor rata-rata dari validasi materi mendapatkan persentase sebesar 90,2\%, yang akan dijabarkan pada Tabel 3 berikut.

\section{Tabel 3. Hasil Validasi Materi}

\begin{tabular}{|c|c|c|}
\hline $\begin{array}{l}\text { Aspek yang } \\
\text { dinilai }\end{array}$ & $\begin{array}{l}\text { Hasil } \\
(\%)\end{array}$ & Kriteria \\
\hline Organisasi materi & 91 & $\begin{array}{l}\text { Sangat } \\
\text { Valid }\end{array}$ \\
\hline $\begin{array}{l}\text { Ruang Lingkup } \\
\text { Materi }\end{array}$ & 93 & $\begin{array}{l}\text { Sangat } \\
\text { Valid }\end{array}$ \\
\hline Akurasi Materi & 95 & $\begin{array}{l}\text { Sangat } \\
\text { Valid }\end{array}$ \\
\hline $\begin{array}{l}\text { Kelayakan } \\
\text { Bahasa dalam } \\
\text { Memahami } \\
\text { Materi }\end{array}$ & 80 & $\begin{array}{l}\text { Sangat } \\
\text { Valid }\end{array}$ \\
\hline $\begin{array}{l}\text { Penyajian } \\
\text { evaluasi }\end{array}$ & 92 & $\begin{array}{l}\text { Sangat } \\
\text { Valid }\end{array}$ \\
\hline Rata-rata Skor & 90,2 & $\begin{array}{l}\text { Sangat } \\
\text { Valid }\end{array}$ \\
\hline
\end{tabular}

Evaluasi berdasarkan hasil validasi oleh ahli materi sebagai berikut:

a) Komponen kemenarikan

Berdasarkan materi secara keseluruhan sangat menarik, karena menampilkan hasil penelitian laboratorium tentang DM yang dikaitkan dengan materi sistem peredaran darah sebagai wawasan baru bagi mahasiswa. selain itu model pembelajran inkuiri sebagai langkah pebelajaran dalam modul dapat mengembangkan keterampilan mahaiswa dalam melakukan kegiatan ilmiah.

b) Kelayakan

Modul sudah memenuhi kelayakan baik modul untuk mahasiswa maupun pegangan bagi Dosen, karena dalam modul terdapat hasil penelitian yang relevan dan kegiatan praktikum, sehingga membantu mahasiswa dalam memahami sebuah konsep, namun masih perlu beberapa perbaikan dari segi gambar/ilustrasi, tujuan pembelajaran yang lebih diperjelas, kurang adanya petunjuk pengerjaan soal pada self assesment, dan perlunya kesesuaian antara skor penilaian dengan jawaban soal pada kegiatan inkuiri.

c) Kelebihan

Setiap BAB dalam modul menampilkan pendekatan kontekstual yang terdapat dalam tahapan eksplorasi fenomena dalam kegiatan inkuiri. Serta bahasa yang mudah dipahami sesuai dengan karakter mahasiswa IKIP Budi Utomo Malang.

d) Saran

Keterangan gambar/bagan dengan istilah asing diperbaiki dengan menambahkan keterangan menggunakan bahasa Indonesia, agar mahasiswa mudah memahami, penulisan rujukan di seragamkan, dan perlunya memperjelas cara kerja pada tahap penelitian DM, serta perlu menambahkan kata yang kurang dipahami pada glosarium.

Selanjutnya valiadasi bahan ajar bertujuan untuk menguji kevalidan bahan ajar dari segi isi dan desain modul. Modul yang dikembangkan adalah untuk mahasiswa dan dosen pengampu matakuliah. Berdasarkan hasil evaluasi didapatkan skor rata-rata sebesar $94,75 \%$ untuk modul 
mahaisiswa dan 94\% untuk modul pegangan Dosen yang akan dijabarkan sebagai berikut pada Tabel 4:

Tabel 4. Hasil Validasi Ahli Pengembangan Bahan Ajar untuk Modul Mahasiswa

\begin{tabular}{|c|c|c|c|}
\hline $\begin{array}{l}\text { Aspek } \\
\text { yang } \\
\text { dinilai } \\
\end{array}$ & $\begin{array}{l}\text { Modul } \\
\text { mahasis } \\
\text { wa }(\%) \\
\end{array}$ & $\begin{array}{l}\text { Modul } \\
\text { dosen } \\
(\%)\end{array}$ & $\begin{array}{l}\text { Krite } \\
\text { ria }\end{array}$ \\
\hline $\begin{array}{l}\text { Kelayakan } \\
\text { Isi }\end{array}$ & 98 & 95 & $\begin{array}{l}\text { Sang } \\
\text { at } \\
\text { Valid }\end{array}$ \\
\hline $\begin{array}{l}\text { Kebermakn } \\
\text { aan Modul }\end{array}$ & 92 & 92 & $\begin{array}{l}\text { Sang } \\
\text { at } \\
\text { Valid }\end{array}$ \\
\hline $\begin{array}{l}\text { Komponen } \\
\text { Kelayakan } \\
\text { Bahasa }\end{array}$ & 93 & 93 & $\begin{array}{l}\text { Sang } \\
\text { at } \\
\text { Valid }\end{array}$ \\
\hline Kegraf & 96 & 96 & $\begin{array}{l}\text { Sang } \\
\text { at } \\
\text { Valid }\end{array}$ \\
\hline $\begin{array}{c}\text { Rata-rata } \\
\text { Skor }\end{array}$ & 94,75 & 94 & $\begin{array}{l}\text { Sang } \\
\text { at } \\
\text { Valid }\end{array}$ \\
\hline
\end{tabular}

Evaluasi berdasarkan hasil validasi oleh pengembangan bahan ajar sebagai berikut:

\section{a) Kemenarikan}

Modul sudah disusun secara menarik, dengan bahasa yang sederhana, banyaknya gambar dan bagan untuk mempermudah pemahaman materi dalam modul.

b) Kelayakan

Komponen dalam modul lengkap, dan sangat layak di implementasikan di kelas dengan beberapa perbaikan, seperti memperjelas langkah kegiatan inkuiri.

\section{c) Kelebihan}

$$
\text { Menampilkan pendekatan }
$$

kontekstual dengan hasil penelitian, modul dapat melatih keterampilan proses melalui kegiatan inkuiri. Prosedur penelitian DM yang dikembangkan jelas dan menarik untuk dipelajari.

\section{d) Saran}

Perlunya memperjelas pedoman penilaian untuk menilai kegiatan inkuiri pada modul dosen. Secara keseluruhan, modul yang dikembangkan layak dan dapat diterapkan di dalam kelas.

Pengembangan modul juga divalidasi oleh praktisi pembelajaran yaitu dosen yang mengampu matakuliah anatomi fisiologi manusia di IKIP Budi Utomo Malang untuk menguji kevalidan dan kepraktisan modul. Hasil dari pengisian instrument penialian produk yang dikembangkan dijabarkan pada Tabel. 5 berikut:

Tabel 5. Hasil Validasi Praktisi Pembelajaran

\begin{tabular}{|c|c|c|}
\hline $\begin{array}{c}\text { Aspek yang } \\
\text { dinilai }\end{array}$ & $\begin{array}{c}\text { Hasil } \\
(\%)\end{array}$ & Kriteria \\
\hline $\begin{array}{l}\text { Kejelasan } \\
\text { komponen dalam } \\
\text { modul }\end{array}$ & 97 & $\begin{array}{l}\text { Sangat } \\
\text { Valid }\end{array}$ \\
\hline $\begin{array}{l}\text { Ruang Lingkup } \\
\text { Materi }\end{array}$ & 95 & $\begin{array}{l}\text { Sangat } \\
\text { Valid }\end{array}$ \\
\hline $\begin{array}{l}\text { Kemandirian } \\
\text { modul }\end{array}$ & 100 & $\begin{array}{l}\text { Sangat } \\
\text { Valid }\end{array}$ \\
\hline $\begin{array}{l}\text { Kesesuaian } \\
\text { materi yang } \\
\text { disampaikan } \\
\text { dengan } \\
\text { perkembangan } \\
\text { IPTEK }\end{array}$ & 100 & $\begin{array}{l}\text { Sangat } \\
\text { Valid }\end{array}$ \\
\hline $\begin{array}{l}\text { Aspek } \\
\text { pembelajaran }\end{array}$ & 91 & $\begin{array}{l}\text { Sangat } \\
\text { Valid }\end{array}$ \\
\hline Rata-rata Skor & 96,6 & $\begin{array}{l}\text { Sangat } \\
\text { Valid }\end{array}$ \\
\hline
\end{tabular}

Evaluasi berdasarkan hasil validasi oleh praktisi pembelajaran sebagai berikut:

a) Kemenarikan

Modul yang dikembangkan memuat materi yang kekinian yang diperoleh dari hasil penelitian sehingga memuat konsep-konsep kebaharuan. 
b) Kelayakan

Modul layak digunakan dalam pembelajaran untuk mengembangkan kompetensi mahasiswa.

c) Kelebihan

Modul terstruktur dengan jelas sesuai dengan pembelajarn inkuiri, bahasa yang sederhana, dan menarik untuk dipelajari. Aspek kemandirian modul dan kesesuaian materi sudah sesuai dengan IPTEK karena sudah memuat hasil penelitian, sehingga diharapkan dapat memberikan wawasan yang lebih kepada mahasiswa terhadap perkembangan IPTEK.

d) Saran

Cakupan materi lebih luas, tidak hanya pada materi sistem peredaran darah tapi dapat dikaitkan dengan materi lain pada matakuliah anatomi fisiologi manusia.

\section{d. Implement}

Produk modul yang telah direvisi berdasarkan masukan dari ahli materi, pengembangan bahan ajar, dan praktisi pembelajaran, dapat diujicobakan dalam pembelajaran serta pengisian angket kepada kelompok kecil yaitu keompok kecil dan kelompok besar yaitu mahasiswa yang telah menempuh dan yang sedang menempuh matakuliah Anatomi Fisiologi Manusia.

Uji coba kelompok kecil diberikan pada 9 mahasiswa, dan 23 mahasiswa pada kelompok besar yang telah menempuh matakuliah anatomi fisiologi manusia, hasil angket yang diberikan terdiri dari 3 aspek yang akan dijabarkan pada Tabel 6.

\begin{tabular}{|c|c|c|c|}
\hline Tabel 6. & $\begin{array}{l}\text { Hasil A } \\
\text { Kelompo } \\
\text { Kelompo }\end{array}$ & $\begin{array}{l}\text { gket L } \\
\text { Kec } \\
\text { Besar }\end{array}$ & $C$ \\
\hline Aspek & $\begin{array}{l}\text { Modul } \\
\text { mahasis } \\
\text { wa }(\%)\end{array}$ & $\begin{array}{l}\text { Modul } \\
\text { dosen } \\
(\%)\end{array}$ & $\begin{array}{l}\text { Krite } \\
\text { ria }\end{array}$ \\
\hline $\begin{array}{l}\text { Keterbantu } \\
\text { an proses } \\
\text { pembelajar } \\
\text { an }\end{array}$ & 88,30 & 98 & $\begin{array}{l}\text { Sang } \\
\text { at } \\
\text { Valid }\end{array}$ \\
\hline $\begin{array}{l}\text { Kemenarik } \\
\text { an modul }\end{array}$ & 87,94 & 100 & $\begin{array}{c}\text { Sang } \\
\text { at } \\
\text { Valid }\end{array}$ \\
\hline $\begin{array}{l}\text { Kemudaha } \\
\mathrm{n} \\
\text { penggunaa } \\
\mathrm{n} \text { modul }\end{array}$ & 84,89 & 98 & $\begin{array}{l}\text { Sang } \\
\text { at } \\
\text { Valid }\end{array}$ \\
\hline $\begin{array}{c}\text { Rata-rata } \\
\text { Skor }\end{array}$ & 87,04 & 98,67 & $\begin{array}{c}\text { Sang } \\
\text { at } \\
\text { Valid }\end{array}$ \\
\hline
\end{tabular}

Evaluasi berdasarkan hasil angket kelompok kecil dan kelompok besar sebagai berikut:

a) Kemenarikan

Gambar dan materi yang ada dalam modul menarik untuk dipelajari, dengan menampilkan hasil penelitian yang merupakan hal yang baru.

b) Kelayakan

Layak digunakan untuk membantu pemahaman baik teori maupun prakteknya.

c) Kelebihan

Membantu dalam pelaksanaan praktikum matakuliah anatomi fisiologi manusia khususnya materi sistem peredaran darah.

d) Saran

Kegiatan inkuiri dalam matakuliah anatom fisiologi manusia merupakan hal yang baru, sehingga sedikit kurang memahami langkah inkuiri di modul, maka perlu memperluas materi tidak hanya terpaut pada sistem peredaran darah, agar 
terbiasa melakukan kegiatan inkuiri.

\section{e. Evaluation}

Modul yang dikembangkan mengasilkan produk yang valid, praktis, dan efektif setelah direvisi berdasarkan masukan dari ahli materi, pengembangan bahan ajar, dan praktisi lapangan, dan siap untuk diterapkan pada matakuliah anatomi fisiologi manusia materi sistem peredaran darah di IKIP Budi Utomo Malang sebagai bahan ajar mahasiswa.

Modul sistem peredaran darah berbasis inkuiri berdasarkan hasil penelitian merujuk pada model ADDIE yang dikembangkan oleh Branch et al (2009). Pengembangan modul ini didasari pada kondisi yang ada di lapangan yaitu kebutuhan mahasiswa akan sebuah bahan ajar yang dapat memberikan pengalaman belajar secara langsung, menambah wawasan, dan membantu tercapainya capaian pembelajaran sesuai tuntutan KKNI. Modul yang dikembangkan diharapkan dapat mendorong rasa ingin tahu mahasiswa karena adanya interaksi yang telah dirancang dalam modul sebagai sumber belajar.

Peneliti memilih modul berbasis inkuiri karena kegiatan dari modul mengikuti langkah pembelajaran inkuiri sehingga mahasiswa dapat berinteraksi langsung dengan sumber belajar, dengan begitu akan membantu mahasiswa dalam membangun pengetahunnya berdasar aktivitas dalam kegiatan ilmiah yang dilakukan. Pendapat tersebut sejalan dengan penelitian Mustafa (2010) yang menyatakan model pembelajaran inkuiri menekankan pada pengalaman belajar secara langsung sehingga mahasiswa mampu menarik kesimpulan dari kegiatan ilmiah yang dilakukan.

Pendekatan kontekstual yang ada dalam modul adalah berbasis penelitian berupa penyakit DMT2 dan hasil penelitian DMT2 yang dikaitkan dengan materi sistem peredaran darah akan membantu mahasiswa dalam belajar secara mandiri. Suryawati and Osman (2017) dalam penelitiannya menyatakan pembelajaran yang kontekstual akan memudahkan mahasiswa dalam memahami materi dan menghubungkan teori yang diperolehnya dengan kehidupan seharihari dan lingkungannya.

Pembelajaran kontekstual berbasis riset mampu mewujudkan pembelajaran inspiratif (Slameto 2015) dan mahasiswa juga dapat mengembangkan kemampuan menelitinya (Ranguti, 2016). Leksono (2016) dalam penelitiannya yaitu penerapan pembelajaran riset dengan pendekatan kontekstual melalui kearifan lokal berpengaruh terhadap penguasaan konsep, menumbuhkan kemampuan berkomunikasi, kemandirian belajar, berpikir kritis, kreatif (Ranguti, 2016), dan high order thinking skill (Ramli, 2015).

Hasil yang diperoleh berdasarkan uji coba kelompok kepada mahasiswa menyatakan modul yang menampilkan hasil penelitian DMT2 sangat membantu dan menarik untuk dipelajari untuk menambah wawasan, selain itu kegiatan inkuiri dalam matakuliah anatomi fisiologi manusia masi belum pernah diterapkan sehingga mahasiswa menyambutnya dengan sangat antusias.

Manfaat dari modul tidak hanya bagi mahasiswa, namun dosen pun dapat mengupdate keilmuannya berdasarkan hasil penelitian yang dijabarkan dalam modul. Implementasi modul akan merangsang mahasiswa untuk aktif, sehingga akan menjadi inovasi, ide dan gagasan bagi dosen menjadikan modul sebagai bagian dalam penelitiannya. 
Sebelum diimplementasikan dalam lapangan, modul yang dikembangkan harus melalui proses validasi, tujuannya agar bahan ajar tersebut layak dan mungkin masi perlu diperbaiki (Depdiknas, 2008). Kelayakan modul hasil dari kegiatan penelitian pengembangan modul ini ditentukan oleh 3 kriteria yaitu kevalidan, kepraktisan, dan efektifan. Proses validasi di evaluasi oleh validator sesuai bidang dan keahlian masing-masing melalui instrument penilaian kelayakan modul. Saran dan masukan yang diberikan oleh validaror akan menyempurnakan modul yang dikembangkan menjadi lebih baik. Modul ini akan menjadi pelengkap dari sumber belajar utama mahasiswa dan dosen

\section{KESIMPULAN}

Modul berbasis inkuiri berdasarkan hasil penelitian DMT2 yang dikembangkan dinyatakan sangat valid, dan layak digunakan berdasar penilaian dari validator ahli materi, pengembangan bahan ajar, dan praktisis lapangan, serta uji coba kelompok kecil dan kelompok besar di IKIP Budi Utomo Malang pada materi sisitem peredaran darah.

\section{DAFTAR PUSTAKA}

Abdi, A. 2014. The Effect Of InquiryBased Learning Method On Student's Academic Achievement In Science Course. Universal Journal Of Education Research, 2 (1): 37-41.

Akbar, S. 2013. Instrumen Perangkat Pembelajaran. Bandung: $\mathrm{Pt}$ Remaja Rosdakarya.

Anwar, I. 2010. Pengembangan Bahan Ajar. Bahan Kuliah Online. Bandung: Direktori UPI.
Bayram, Z., Oskay, O.O.O., Erdem, E., Ozgur, S.D., Sen, S. 2013. Effect Of Inquiry Based Learning Method On Sudent's Motivation. Procedia-Social And Behavioral Sciences, 106: 988-996.

Betty, T., Ida, W., Yul Ifda. 2016. The Effect Of Inquiry Training Learning Model Based On Just In Time Teaching For Problem Solving Skill. Journal of Education And Practice, 7 (15) 177-181.

Chung, Hui-Min., Behan, K.J. 2010. Peer Sharing The Effect Of Inquiry -Based Pojects On Science Learning. The American Biology Teacher, 72 (1): 24-29.

Departemen Pendidikan Nasional. 2008.

Pengembangan Bahan Ajar Dan Media. Jakarta: Departemen Pendidikan Nasional.

Dewi, E.P., Agus, S., Abdurrahman., Ertikanto, C. 2017. Efektivitas Modul Dengan Model Inkuiri Untuk Menumbuhkan Keterampilan Proses Sains Siswa Pada Materi Kalor. Tadris: Jurnal Keguruan Dan Ilmu Tarbiyah, 2 (2): 105-110.

Diana, M., Netriwati, \& Suri, F. I. 2018. Modul Pembelajaran

Matematika Bernuansa Islami Dengan Pendekatan Inkuiri. Desimal, 1(1), 7- 13.

Ergul,R., Simsekli,Y., Calis, S., Ozdilek,Z., Gocmencelebi,S., Sanli, M. 2011. The Effects Of Inquiry-Based Science Teaching On Elementary School Students' Science Process Skills And Science Attitudes. Bulgarian Journal of Science and Education Policy (BJSEP), 5 (1): 48-68.

Espinoza, F., Quarless, D. 2010. An Inquiry-Based Contextual 
Approach As The Primary Mode Of Learning Science With Microcomputer-Based

Laboratory Technology. Journal Of Educational Technology System, 38 (4).

Fatmala, S.A., Sujana, A., Maulana, M. 2017. Pembelajaran Kontekstual Untuk Meningkatkan Literasi Sains Siswa Sd Kelas V Pada Materi Peristiwa Alam. Jurnal Pena Ilmiah, 2 (1): 211-20.

Furqan, H., Yusrizal,Y., and Saminan, S. 2016. Pengembangan Modul Praktikum Berbasis Inkuiri Untuk Meningkatkan Keterampilan Proses Sains Dan Hasil Belajar Siswa Kelas X Di Sma Negeri 1 Bukit Bener Meriah. Jurnal Pendidikan Sains Indonesia (Indonesian Journal of Science Education), 04 (02): 124-129.

Jamun, Y.M. 2018. Dampak Teknologi Terhadap Pendidikan, Jurnal Pendidikan dan Kebudayaan Missio. 10 (1): 48-52.

Karlina, F.D., Sajidan,S., and Karyanto, P. 2018. Pengembangan Modul Berbasis Inquiry Lab Untuk Meningkatkan Kemampuan Menganalisis Pada Materi Sistem Gerak Kelas XI IPA. Inkuiri: Jurnal Pendidikan IPA, 7(1): 71-80.

Kemenristekdikti. 2016. Panduan Penyusunan Kurikulum

Pendidika Tinggi. Jakarta:

Direktorat Jenderal

Pembelajaran dan

Kemahasiswaan kementrian iset Teknologi dan Pendidikan Tinggi.

Leksono, S.M. 2016. Pengaruh Pembelajaran Mini Riset Berbasis Kearifan Lokal Terhadap Kemampuan Penguasaan Materi Biologi
Konservasi. Proceeding Biology Education Conference, 13 (1): 575-578.

Mustafa, S. 2010. Penerapan strategi inkuiri sebagai upaya meningkatkan hasil belajar matematika siswa kelas X SMA Negeri 4 Parepare oleh Sriyanti Mustafa. Tesis. Malang: Pascasarjana Program Studi Pendidikan Matematika.

Muzaffar, K., Iqbal., Zafar, M. Effect Of Inquiry Lab Teaching Method On The Development Of Scientific Skills Throught The Teaching Of Biology In Pakistan. Language In India, 11 (1): 169-178

Nurochma, R., Maridi., \& Ariyanto, J. 2012. Perbedaan Hasil Belajar Dengan Penerapan Model Pembelajaran Guided Inquiry dan Demonstrasi ditinjau dari Gaya Belajar Siswa Kelas VIII SMP Negeri 1 Jaten. Skripsi. Universitas Sebelas Maret

Ozgur, S.D., Yilmaz, A. 2017. The Effect Of Inquirybased Learning On Gifted And Talented Students' Understanding Of Acidsbases Concepts And Motivation. Journal of Balitic Science Education, 16 (6): 9941008.

Pratiwi, P. H., Hidayah, N., \& Martiana, A. 2017. Pengembangan Modul Mata Kuliah Penilaian Pembelajaran Sosiologi Berorientasi HOTS. Cakrawala Pendidikan, 36(2), 201-208.

Puspitasari, A. D., 2019. Penerapan Media Pembelajaran Fisika Menggunakan Modul Cetak Dan Modul Elektronik Pada Siswa SMA. Jurnal Pendidikan Fisika, 7 (1): 17-25.

Ramli, M. 2015. Implementasi Riset Dalam Pengembangan Higher 
Order Thinking Skills Pada Pendidikan Sains. Prosiding Seminar Nasional Pendidikan Sains $V$ Magister Pendidikan Sains dan Doktor Pendidikan IPA FKIP UNS, 6-17

Slameto. 2015. Pembelajaran Berbasis

Riset Mewujudkan

Pembelajaran Yang Inspiratif. Satya Widya, 31 (2): 102-113.

Supriyadi and Waremra, R.S. 2019.

Papua Contextual Science

Curriculum Contains With

Indigenous Science

(Ethnopedagody Study At

Malind Tribe Merauke).

International Journal of Civil

Engineering And Teaching

(IJCIET), 10 (1): 1994-2000.

Suryawati, E., Osman, K. Contextual

Learning: Innovative Approach

Towards The Development Of

Student's Scientific Attitude

And Natural Science

Performance. EURASIA Journal

Of Mathematics, Science And

Technology Education, 14 (1):

61- 76.

Tangi, H. 2016. Pengruh Model Pembeljaran Berbasis Riset Terhadap Hasil Belajar Mahasiswa Kimia. Jipera: Jurnal Inovasi Pendidikan Unwira, 1(1): 2503-2534

Umar, M.K., Yusuf, M., Supartin., Uloli, R., Abjul, Tirtawaty., Ntobuo, $\quad$ N.E. 2011.

Pengembangan Pembelajaran Berbasis Riset Di Program Studi Pendidikan Fisika Laporan Hasil Penelitian. Gorontalo: Universitas Negeri Gorontalo.

Utami, T.N., Jatmiko, A., Suherman. 2018. Pengembangan Modul Matematika Dengan Pendekatan Science, Technology, Engineering, And Mathematics (STEM) Pada Materi Segiempat,
Desimal:Jurnal Matematika, 1 (2): 165-172.

Vlassi, M., and Karaliota, A. 2013. The Comparison between Guided Inquiry and Traditional Teaching Method. A Case Study for the Teaching of the Structure of Matter to 8th Grade Greek Students. Procedia - Social and Behavioral Sciences, 93 (1): 494-497.

Widayati, D.T., dkk. 2010. Pedoman Umum Pembelajaran Berbasis Riset. Yogyakarta: Universitas Gadjah Mada.

Yulita, E. 2018. Pengembangan Modul Pembelajaran IPA Berbasis Inkuiri Terbimbing untuk Meningkatkan Keterampilan Proses Dasar Sains Peserta Didik Kelas IV MI/SD. Journal of Madrasah Ibtidaiyah Education, 2 (2): 165-180. 